\title{
Inhibiting action of amino-heterocyclic compounds under conditions of iron corrosion in sulfuric acid solutions
}

\author{
V.P. Grigor'ev ${ }^{\dagger},{ }^{1}$ E.V. Plekhanova, ${ }^{2}$ E.G. Drogan, ${ }^{2}$ L.D. Popov ${ }^{1}$ and \\ T.G. Plekhanova*
}

${ }^{1}$ Southern Federal University, ul. Zorge 7, 344090 Rostov-on-Don, Russian Federation

${ }^{2}$ Don State Technical University, Gagarin sq. 1, 344000 Rostov-on-Don, Russian

Federation

${ }^{3}$ Shakhty Automobile and Road Institute (branch), South Russian State Polytechnic

University (NPI) named after M.I. Platova, Lenin sq. 1, 346500 Shakhty, Russian

Federation

*E-mail: plekhanova.elizaveta@yandex.ru

\begin{abstract}
Amino-heterocyclic compounds were studied as acid corrosion inhibitors. The gravimetric method was used to determine the degree of protection of the studied compounds during iron corrosion in $1 \mathrm{M} \mathrm{H}_{2} \mathrm{SO}_{4}$ solution at various concentrations of compounds over a wide temperature range. The values of the corrosion inhibition coefficients $K$ of iron under the conditions studied depend on the inhibitor concentration in the solution. Based on the data of gravimetric and temperature-kinetic measurements, the effective activation energy of the corrosion process was determined. Potentiostatic measurements were carried out in a threeelectrode cell with a platinum auxiliary electrode and a silver-silver chloride reference electrode. Suppression of metal dissolution occurs both in the cathodic and anodic regions, but these substances inhibit the cathodic rather than anodic reaction. Partial inhibition coefficients were calculated from polarization measurements. It was found that the test substances are mixed-type inhibitors with a predominant blocking effect. With an increase in concentration, the contribution of the blocking factor to the protective effect of the inhibitor decreases, while the contribution of the activation component increases. An explanation of these facts is given based on the structure of the compounds studied. The AFM method was used to determine the efficiency of the additives as inhibitors. The surfaces of metals treated with both pure acid and inhibited solutions were studied. AFM images of the samples after the corrosion tests in the presence of inhibitors demonstrate the absence of damage, smoothing and levelling of the metal surfaces.
\end{abstract}

Keywords: inhibitor, corrosion, corrosion inhibition coefficient, adsorption.

Received: March 17, 2020. Published: May 12, 2020

doi: $\underline{10.17675 / 2305-6894-2020-9-2-13}$ 


\section{Introduction}

The acid corrosion of many structural materials is associated with their very low thermodynamic stability in acidic environments. The complexity and ambiguity of the corrosion processes does not allow one to predict a priori the life of the material under these specific conditions.

However, analysis of the current state of the problem showed that classes of compounds among which efficient corrosion inhibitors of metallic materials should be sought can be predicted with a sufficient degree of certainty. In particular, nitrogen-containing organic compounds have long been known as efficient inhibitors of acid corrosion of metals. Despite the wide range of studies conducted in this area, studies of new organic inhibitors continue to be an urgent task in modern industrial production.

Organic nitrogen-containing compounds have long been known as efficient inhibitors of acid corrosion of metals [1-3]. Aliphatic, aromatic and heterocyclic amides, amines, quinolines and other compounds have been studied most thoroughly in this regard $[4,5]$. In this work, we studied the behavior of three organic compounds of the class of aminoheterocycles of pyridine and uracil series as inhibitors of iron corrosion. Due to the presence of an amino group and endocyclic nitrogen atoms, they are able to be adsorbed on a metal surface and form covalent chemical bonds with the metal. In this regard, the aim of this work was to study the inhibitory effect of new organic substances on the corrosion of iron in sulfuric acid solutions.

\section{Experimental}

Corrosion tests were performed according to GOST 9.505-86 using samples of St3 steel in $1 \mathrm{M}$ sulfuric acid solutions. The following substances were studied as corrosion inhibitors:<smiles>Cc1cccc(N)n1</smiles><smiles>Nc1ncccc1O</smiles><smiles>Nc1c[nH]c(=O)[nH]c1=O</smiles> 
The corrosion test procedure is described in detail in $[6,7]$. The temperature of the solutions was varied in the range of $20-60^{\circ} \mathrm{C}$ using a "Memmert WNB 7-45" laboratory water bath.

The corrosion rate of metals $(j)$ was calculated by the formula:

$$
j=\frac{\Delta m}{S \cdot t}
$$

where $\Delta m$ is the mass loss of the sample, $\mathrm{g} ; t$ is the corrosion time, hours; $S$ is the surface area of a sample, $\mathrm{m}^{2}$.

The protective effect of the compounds was estimated as the inhibition coefficient $(K)$ and the degree of protection $(Z)$ :

$$
\begin{gathered}
K=\frac{j}{j_{\mathrm{i}}} \\
Z=\left(1-\frac{1}{K}\right),
\end{gathered}
$$

where $j$ and $j_{\mathrm{i}}$ are the corrosion rates in the pure and inhibited acid.

The effective activation energies of corrosion $W$ were determined from the temperature plots using the formula:

$$
W=-2.3 R \operatorname{tg} \alpha,
$$

where $\operatorname{tg} \alpha$ is the angular coefficient of the $\log j-1 / T$ plot.

Polarization tests were carried out by the potentiostatic method. Using the Ecolab 2A500 potentiostat, a specific potential was applied to the electrode and the corresponding current value was recorded.

The surface topography of iron samples was studied using a PHYWE Compact AFM scanning probe microscope in the dynamic mode of operation with a TAP190-AlG probe in the semi-contact scanning mode. Scanning was carried out with a single-crystal aluminumcoated silicon probe with a resonant frequency of $190 \pm 60 \mathrm{kHz}$ and a constant hardness of $48 \mathrm{~N} / \mathrm{m}$. The scan rate was $0.3 \mathrm{~ms} /$ line.

\section{Results and Discussion}

The substances studied provide an inhibitory effect under acid corrosion conditions with a good degree of protection.

Corrosion test data are presented in Figure 1. 


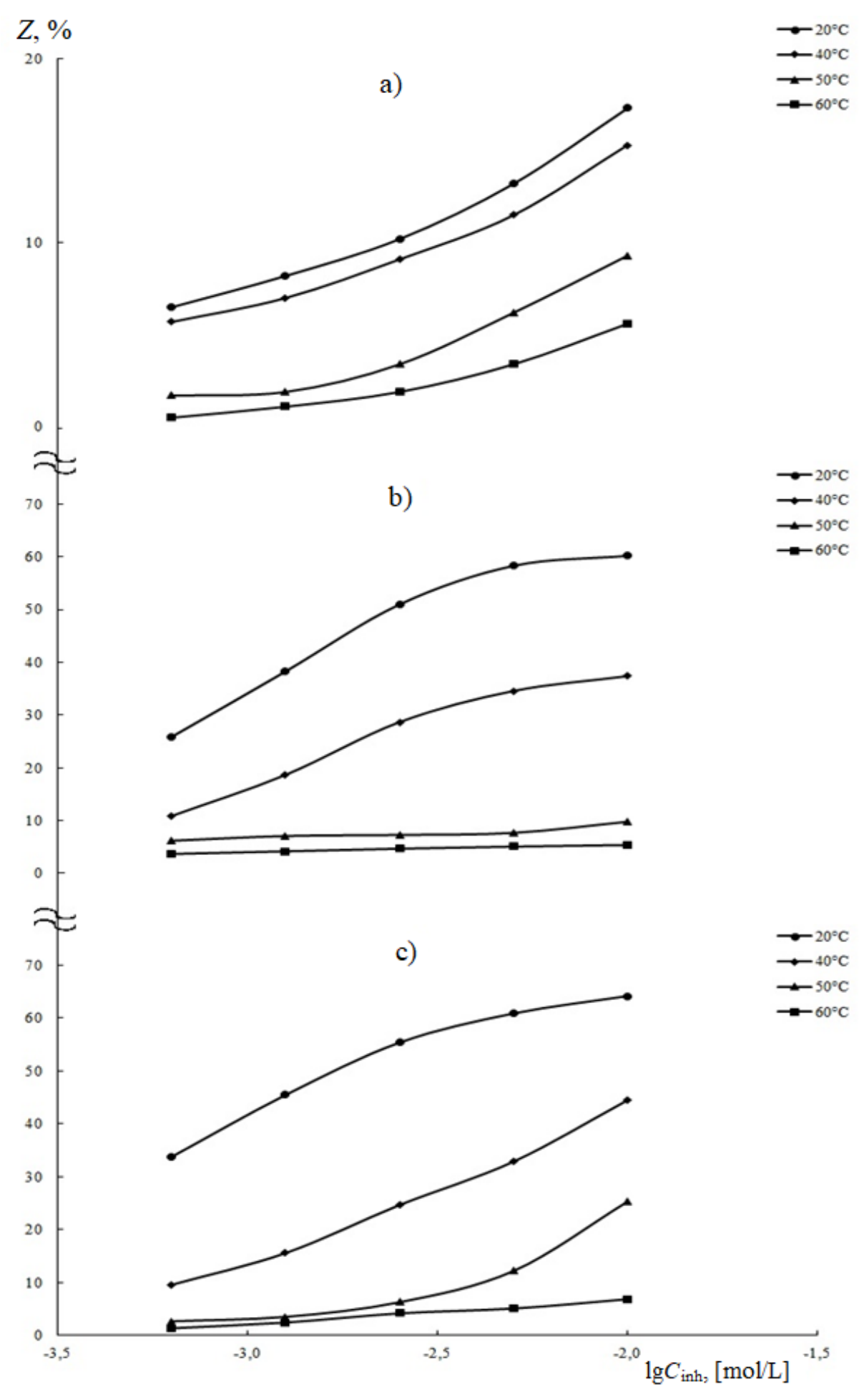

Figure 1. Dependence of the iron corrosion inhibition coefficient $K$ in $1 \mathrm{M} \mathrm{H}_{2} \mathrm{SO}_{4}$ on the concentration of the organic inhibitor: $\mathbf{1}$ (a), $\mathbf{2}$ (b), $\mathbf{3}$ (c), at various temperatures.

It can be concluded from the data obtained that these substances are acid corrosion inhibitors and that the degree of protection increases with an increase in inhibitor concentration and decreases with an increase in temperature. 
The effective activation energy $W$ of the corrosion process in the background solution and in the presence of various concentrations of the inhibitors was determined from the $j-$ temperature plots by the Arrhenius equation $\left(\lg j=A-\frac{W}{2.3 R T}\right)$. The values of $W$ are shown in Figure 2.

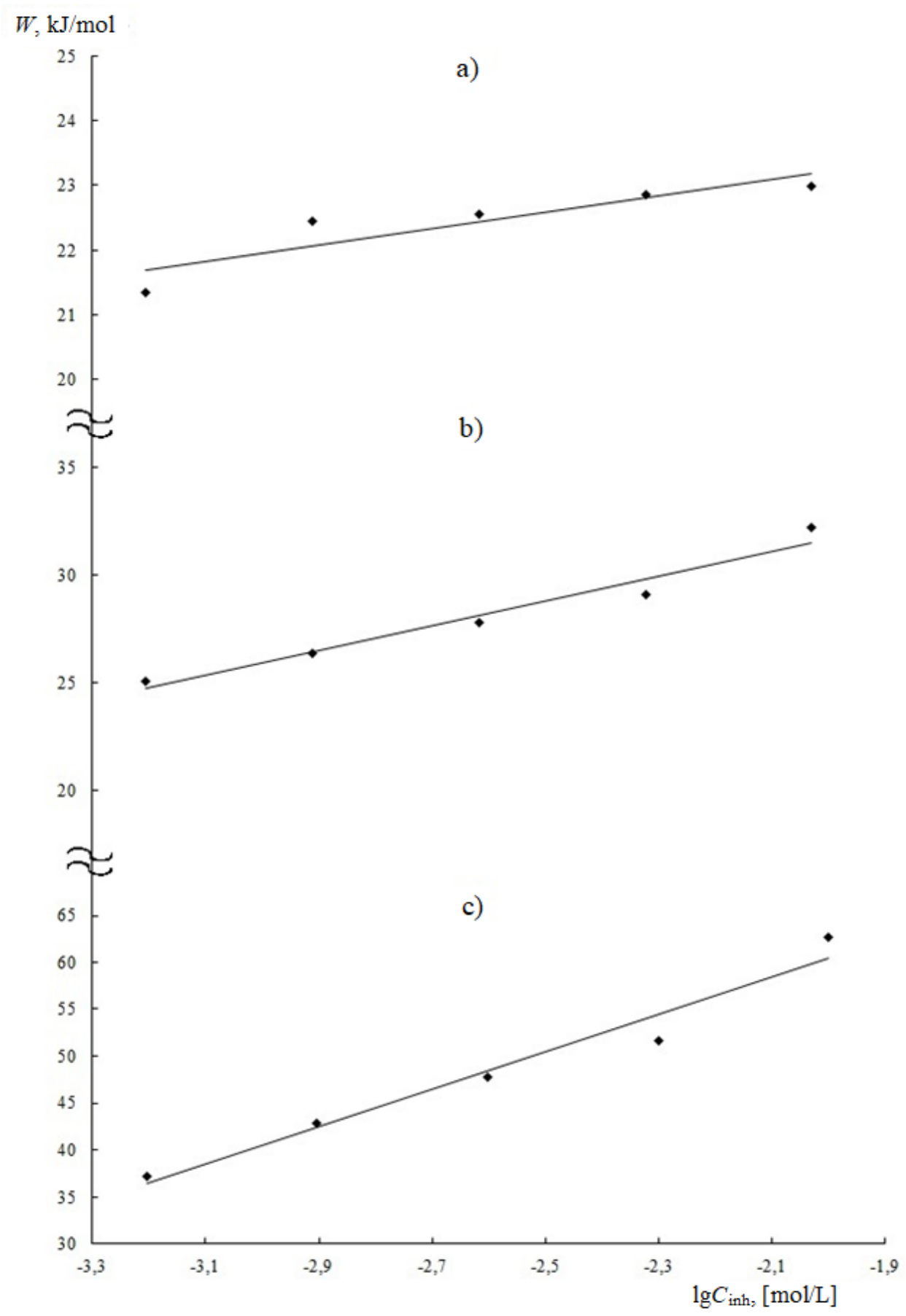

Figure 2. Dependence of the effective activation energy of iron corrosion on the inhibitor concentration: 1 (a), 2 (b), 3 (c). 
Analysis of the above experimental data allowed us to determine that the inhibition process takes place with diffusion control for inhibitor $1(8-25 \mathrm{~kJ} / \mathrm{mol})$, mixed kinetics is characteristic of the second one, and for inhibitor 3 the process occurs with discharge delayed stage (indicating kinetic control of iron self-dissolution) (40-120 kJ/mol) [8].

To determine the mechanism of the protective action of the organic inhibitors, polarization curves were obtained for the background and inhibited solutions at various concentrations.

Based on the data obtained, polarization curves were built in the $E-\lg i$ coordinates.

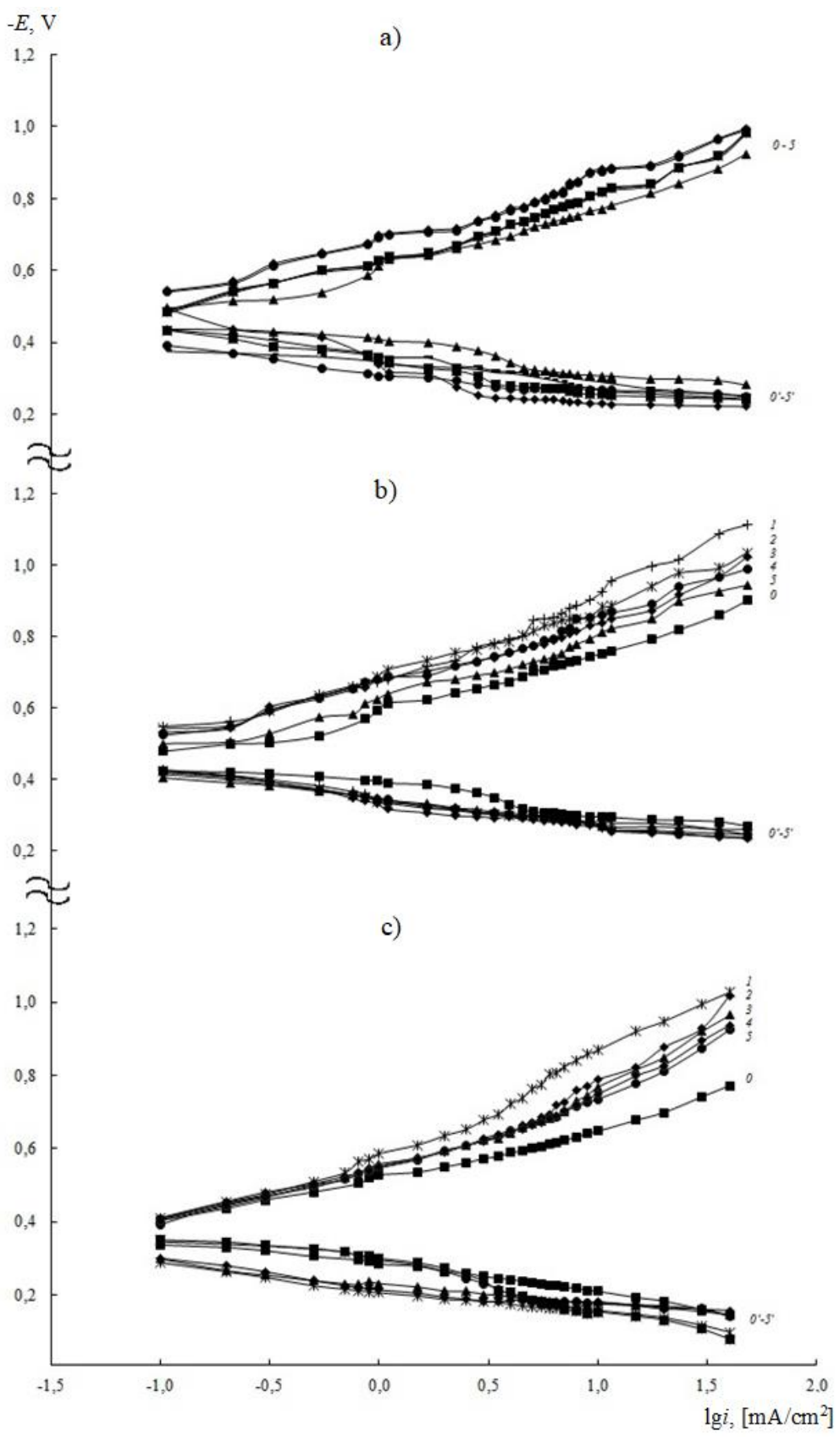

Figure 3. Polarization curves at $20^{\circ} \mathrm{C}$ and at concentrations of inhibitors $\mathbf{1}$ (a), 2 (b), $\mathbf{3}$ (c), $\mathrm{mol} / \mathrm{L}: 0,0^{\prime}-0 ; 1,1^{\prime}-10^{-2}, 2,2^{\prime}-5 \cdot 10^{-3}, 3,3^{\prime}-2.5 \cdot 10^{-3}, 4,4^{\prime}-1.25 \cdot 10^{-3}, 5,5^{\prime}-0.625 \cdot 10^{-3}$. 
Based on the plots presented in Figure 3, it can be concluded that suppression of metal dissolution occurs both in the cathodic and anodic regions, but these compounds inhibit the cathodic reaction to a greater extent than the anodic one.

Based on the polarization curves, the $b_{\mathrm{a}}$ and $b_{\mathrm{c}}$ coefficients for the Tafel plots were obtained and the $K_{\Psi^{\prime}}$ values were calculated by the formula:

$$
\lg K_{\Psi^{\prime}}=\frac{b_{\mathrm{a}} \cdot b_{\mathrm{c}}}{b_{0} \cdot\left(b_{\mathrm{a}}+b_{\mathrm{c}}\right)}
$$

where $b_{0}=2.3 \frac{R T}{F}$,

$b_{\mathrm{a}}$ is the Tafel slope of the anodic polarization curve on iron, $b_{\mathrm{c}}$ is the Tafel slope of the cathodic polarization curve on iron.

Using the equation of Antropov's formal theory [9, 10]

$$
K=K_{\theta} \times K_{\Psi^{\prime}},
$$

the particular corrosion inhibition coefficients were calculated.

Based on the data obtained (see Table 1), we can conclude that with increasing concentration, the contribution of the blocking factor to the protective effect of the inhibitors decreases, while the contribution of the activation component increases.

Table 1. Dependence of $K, K_{\theta}, K_{\Psi^{\prime}}$ and $Z$ on the inhibitor concentration.

\begin{tabular}{ccccccccccc}
\hline & \multicolumn{3}{c}{ Inhibitor 1 } & \multicolumn{3}{c}{ Inhibitor 2 } & \multicolumn{3}{c}{ Inhibitor 3 } \\
\hline $\begin{array}{c}\boldsymbol{C}_{\text {inh. }} \cdot \mathbf{1 0}^{\mathbf{3}}, \\
\mathbf{m o l} / \mathbf{L}\end{array}$ & $\boldsymbol{K}_{\boldsymbol{\theta}}$ & $\boldsymbol{K}$ & $\boldsymbol{K}_{\boldsymbol{\Psi}^{\prime}}$ & $\boldsymbol{K}_{\boldsymbol{\theta}}$ & $\boldsymbol{K}$ & $\boldsymbol{K}_{\boldsymbol{\Psi}^{\prime}}$ & $\boldsymbol{K}_{\boldsymbol{\theta}}$ & $\boldsymbol{K}$ & $\boldsymbol{K}^{\prime}$ \\
\hline 0.625 & 1.20 & 1.21 & 1.01 & 1.32 & 1.35 & 1.02 & 1.48 & 1.51 & 1.02 \\
1.25 & 1.29 & 1.38 & 1.07 & 1.47 & 1.62 & 1.10 & 1.75 & 1.98 & 1.13 \\
2.5 & 1.57 & 1.74 & 1.11 & 1.69 & 2.04 & 1.21 & 1.76 & 2.24 & 1.27 \\
5 & 1.90 & 2.15 & 1.13 & 1.92 & 2.40 & 1.25 & 1.94 & 2.56 & 1.32 \\
10 & 1.87 & 2.19 & 1.17 & 1.98 & 2.51 & 1.27 & 2.07 & 2.79 & 1.35 \\
\hline
\end{tabular}

According to [11], coverage of an inhomogeneous surface of a solid electrode with organic matter is most likely associated with the compensation effect of two factors: 1) a decrease in the free energy of adsorption with an increase in the degree of surface coverage and 2) an increase in the attractive force between the adsorbed molecules. Also in this case, organic molecules contain atoms with lone electron pairs $(\mathrm{O}, \mathrm{N})$, which, when adsorbed on the most active adsorption centers, can neutralize the energy heterogeneity of the surface iron atoms. Inhibitor $\mathbf{1}$ contains a smaller number of such atoms, which leads to a smaller contribution of the blocking factor to its protective effect, whereas inhibitors $\mathbf{2}$ and $\mathbf{3}$ contain 
3 and 5 atoms with lone electron pairs, respectively. Due to the presence of these atoms, the contribution of the blocking component to the total inhibitory coefficient increases, and it is the greatest in case of inhibitor 3 .

To determine the efficiency of the additives as inhibitors, the AFM method was used, which allows one to obtain geometric representations of the structure of surface layers and additional information on the nature of changes in the metal surface. Comparison of the surface topography in the presence of inhibitors (Figure 5) in 3D images reveals a significant difference in the surface relief $[12,13]$. The 2D images obtained (Figure 4a) indicate an active damage to the surface of the sample and an increase in roughness $[14,15]$.

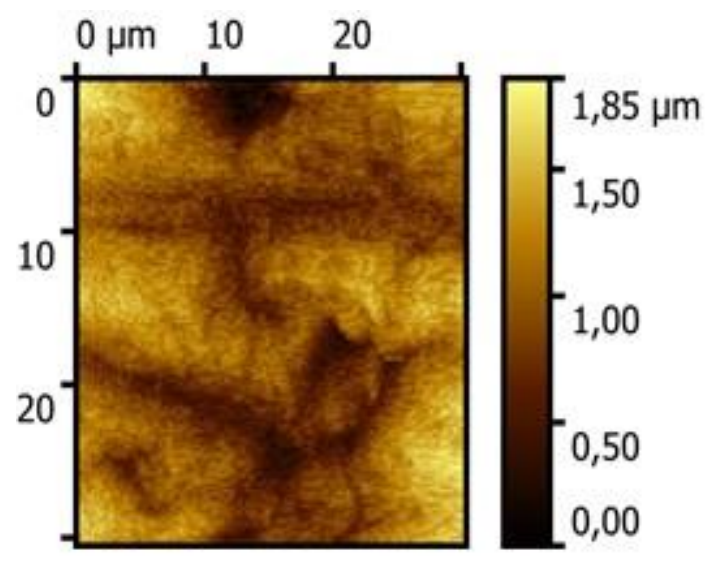

a)

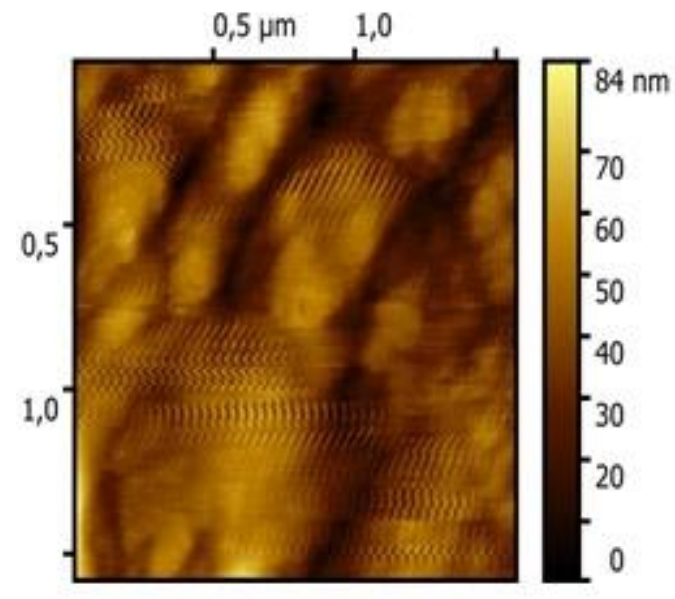

c)

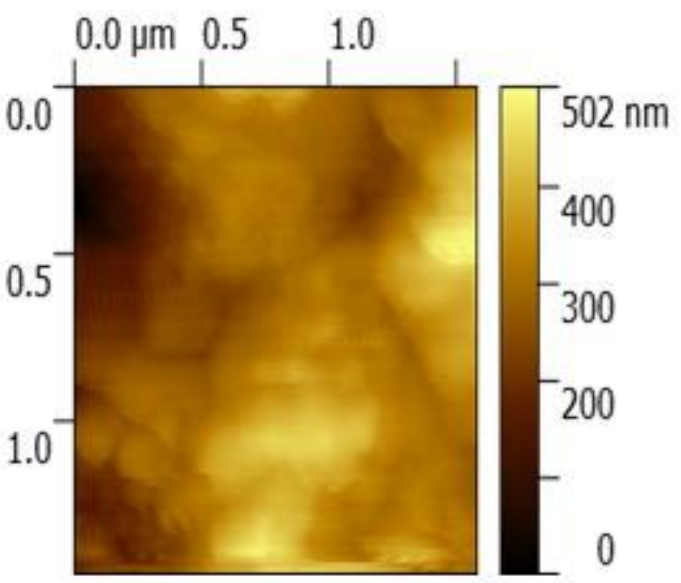

b)

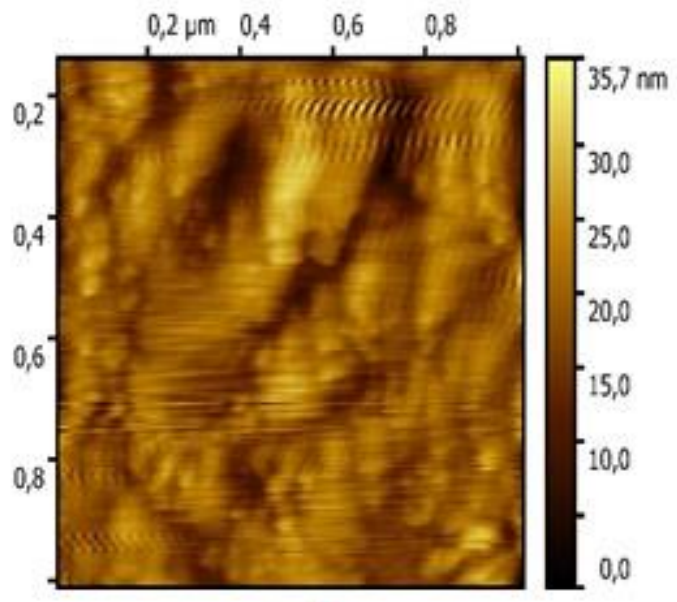

d)

Figure 4. The structure (2D) of the surface according to AFM data: a) a sample kept in $1 \mathrm{M}$ $\mathrm{H}_{2} \mathrm{SO}_{4}$ solution, b) a sample kept in $1 \mathrm{M} \mathrm{H}_{2} \mathrm{SO}_{4}$ solution containing inhibitor 1 , c) a sample kept in $1 \mathrm{M} \mathrm{H}_{2} \mathrm{SO}_{4}$ solution containing inhibitor 2 , d) a sample kept in $1 \mathrm{M} \mathrm{H}_{2} \mathrm{SO}_{4}$ solution containing inhibitor 3 . 
a)

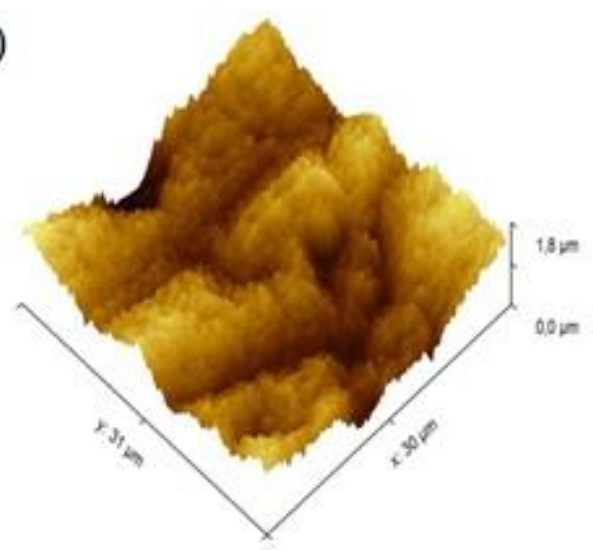

c)

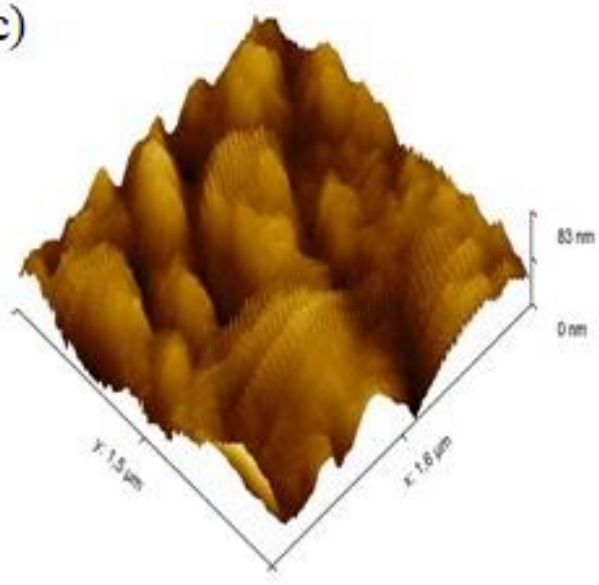

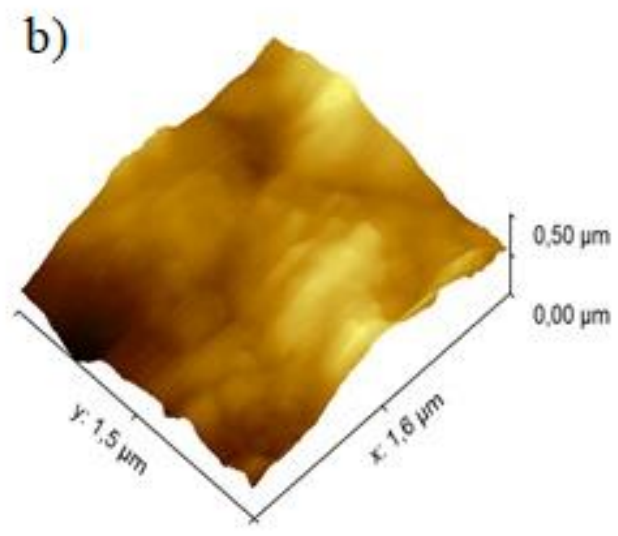

d)

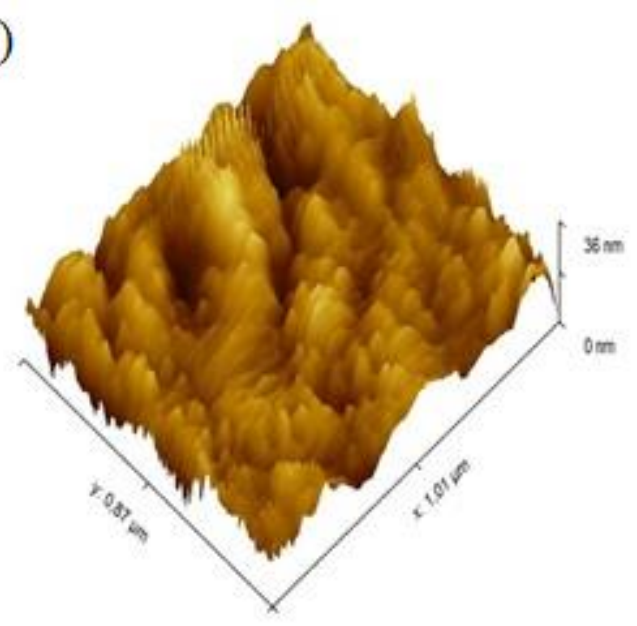

Figure 5. Roughness (3D) of the surface according to AFM data: a) a sample kept in $1 \mathrm{M}$ $\mathrm{H}_{2} \mathrm{SO}_{4}$ solution, b) a sample kept in $1 \mathrm{M} \mathrm{H}_{2} \mathrm{SO}_{4}$ solution containing inhibitor 1, c) a sample kept in $1 \mathrm{M} \mathrm{H}_{2} \mathrm{SO}_{4}$ solution containing inhibitor 2, d) a sample kept in $1 \mathrm{M} \mathrm{H}_{2} \mathrm{SO}_{4}$ solution containing inhibitor 3 .

When considering the AFM image of the sample surface after corrosion tests in the presence of inhibitors (Figure 5b, c, d), one should note the absence of damage, smoothing and levelling of the metal surface, apparently due to the formation of a nanoscale-sized protective layer of the adsorbed inhibitor (about 35-86 nm) [14]. The AFM image of the samples after their testing in sulfuric acid solutions with addition of inhibitor 1, which exhibits a lower blocking inhibitory effect, allows one to detect the formation of a film with a larger thickness (about $86 \mathrm{~nm}$ ) and the formation of larger accumulations of inhibitor molecules. This is expressed in an increase in surface non-uniformity, which leads to greater film porosity and diffusion control during dissolution of iron. 


\section{Conclusions}

1. A new experimental material was obtained on the inhibitory action of organic compounds during the corrosion of $\mathrm{Fe}$ in $1 \mathrm{M} \mathrm{H}_{2} \mathrm{SO}_{4}$. An increase in the concentration of organic compounds increases the corrosion inhibition effect.

2. It was shown that the organic compounds act as mixed type inhibitors in sulfuric acid solutions, but the adsorption component makes a greater contribution to the inhibitory effect.

3. When 5-methyl-2-aminopyridine is adsorbed on the metal surface, a layer about $500 \mathrm{~nm}$ thick is formed with larger and more heterogeneous agglomerations of particles, which provides diffusion control of the corrosion process, while the absorption of 2-amino-3hydroxypyridine results in a thinner layer with smaller and more pronounced particles. The adsorption of 6-aminouracil gives protective layers with a thickness of $c a .40 \mathrm{~nm}$ with visible individual smaller particles providing more efficient protection due to the blocking factor.

\section{References}

1. E. Vázquez-Vélez, J.G. Gonzalez-Rodriguez, M.E. Escalante-Pérez, J.M. Mendoza and L. Martínez-Gómez, Use of fatty amide and anionic surfactant as corrosion inhibitors for carbon steel in different atmospheres, Int. J. Corros. Scale Inhib., 2019, 8, no. 1, $123-$ 138. doi: $10.17675 / 2305-6894-2019-8-1-11$

2. A.I. Obike, P.C. Okafor, K.J. Uwakwe, X. Jiang and D. Qu, The inhibition of $\mathrm{CO}_{2}$ corrosion of $\mathrm{L} 360$ mild steel in $3.5 \% \mathrm{NaCl}$ solution by imidazoline derivatives, Int. J. Corros. Scale Inhib., 2018, 7, no. 3, 318-330. doi: 10.17675/2305-6894-2018-7-3-3

3. Ya.G. Avdeev, D.S. Kuznetsov, M.V. Tyurina, S.V. Oleynik and M.A. Chekulaev, High-temperature inhibitors of stainless steel corrosion in hydrochloric acid solutions, Int. J. Corros. Scale Inhib., 2017, 6, no. 2, 180-195. doi: 10.17675/2305-6894-2017-62-7

4. S.A. Mrani, S. El Arrouji, K. Karrouchi, F. El Hajjaji, K.I. Alaoui, Z. Rais and M. Taleb, Inhibitory performance of some pyrazole derivatives against corrosion of mild steel in $1.0 \mathrm{M} \mathrm{HCl}$ : Electrochemical, MEB and theoretical studies, Int. J. Corros. Scale Inhib., 2018, 7, no. 4, 542-569. doi: 10.17675/2305-6894-2018-7-4-5

5. J. Telegdi, N-Substituted unusual amino acids as corrosion inhibitors. Part IV: N-Acyl derivatives of unnatural amino acids with double bond, Int. J. Corros. Scale Inhib., 2016, 5, no. 5, 360-366. doi: 10.17675/2305-6894-2016-5-4-6

6. S.P. Shpan'ko, V.P. Grigor'ev, E.V. Plekhanova and V.A. Anisimova, Inhibitive and residual protective effects of benzimidazole derivative upon acid corrosion of iron, Fizikokhimiya poverkhnosti $i$ zashchita materialov (Protection of Metals and Physical Chemistry of Surfaces), 2010, 46, no. 2, 255-260 (in Russian). 
7. V.P. Grigor'ev, N.A. Belousova, E.V. Plekhanova and A.S. Burlov, Inhibitive properties of some chelates and their ligands in acid corrosion of zinc, Int. J. Corros. Scale Inhib., 2014, 3, no. 3, 204-214. doi: 10.17675/2305-6894-2014-3-3-204-214

8. A.G. Berezhnaya, Gh.A.H. Shayea and V.V. Chernyavina, Mixtures of substituted pyridinium perchlorates with sulfur-containing organic compounds as inhibitors of acid corrosion of steel, Int. J. Corros. Scale Inhib., 2017, 6, no. 4, 372-383. doi: 10.17675/2305-6894-2017-6-4-2

9. S.M. Reshetnikov, Ingibitory kislotnoi korrozii metallov (Inhibitors of acid corrosion of metals), 1986, Khimiya, Leningrad, 142 (in Russian).

10. L.I. Antropov, Formal theory of the action of organic corrosion inhibitors, Fizikokhimiya poverkhnosti $i$ zashchita materialov (Protection of Metals and Physical Chemistry of Surfaces), 1977, 13, no. 4, 387-399 (in Russian).

11. B.B. Damaskin, O.A. Petry and V.V. Batrakov, Adsorbtsiya organicheskikh soyedineniy na elektrodakh (Adsorption of organic compounds on electrodes), 1968, Nauka, Moscow, 333 (in Russian).

12. M. Mobin and M.A. Khan, Adsorption and corrosion inhibition behavior of polyethylene glycol and surfactants additives on mild steel in $\mathrm{H}_{2} \mathrm{SO}_{4}$, J. Mater. Eng. Perform., 2014, 23, no. 1, 222-229. doi: $10.1007 / \mathrm{s} 11665-013-0767-9$

13. J. Telegdi and T. Abohalkuma, Influence of the nanolayer' post-treatment on the anticorrosion activity, Int. J. Corros. Scale Inhib., 2018, 7, no. 3, 352-362. doi: 10.17675/2305-6894-2018-7-3-6

14. S. John, M. Kuruvilla and A. Joseph, Surface morphological and impedance spectroscopic studies on the interaction of polyethylene glycol (PEG) and polyvinyl pyrrolidone (PVP) with mild steel in acid solutions, Res. Chem. Intermed., 2013, 39, no. 3, 1169-1182. doi: 10.1007/s11164-012-0675-X

15. S.A. Umoren, C. Pan, Y. Li and F.H. Wang, Elucidation of mechanism of corrosion inhibition by polyacrylic acid and synergistic action with iodide ions by in-situ AFM, J. Adhes. Sci. Technol., 2014, 28, no. 1, 31-34. doi: 10.1080/01694243.2013.816836 